\title{
Comparison of Thermographic Imaging and Other Diagnostic Techniques in Diagnosis of Cattle with Laminitis
}

\author{
Mustafa Arican', Fatih Hatipoglu' ${ }^{2}$, Hanifi Erol ${ }^{3}$, Ozgur Kanat ${ }^{4}$, Orhan Yavuz ${ }^{5}$, Kurtulus Parlak' \& Osman Koc ${ }^{6}$
}

\begin{abstract}
Background: Lameness results in major economic losses on dairy farms. The proportion of lameness in cows are between $4-55 \%$, the origin of $90 \%$ lameness are caused by foot diseases. Hoof abnormalities such as laminitis are major contributors to lameness. Aim of the study, compared with thermographic imaging (IRT) and radiographic, magnetic resonans (MR), computer tomography (CT), histopathological analysis on the diagnosis of laminitis.

Materials, Methods \& Results: Preliminary, the animals (20 Holstein-Fresian) were selected by lameness examination for evaluation of the for any obvious signs of disease. The animals were examined when rising and walking of the free stalls. Walking was very painful and clinical symptoms of general distress become present for laminitic group. The cows were scored on a 1 to 5 scale for their locomotion $(1=$ normal locomotion; $5=$ severely lame). Thermographic examinations were performed the all animals after the routine clinical examination methods. The infrared images were taken from the dorsal view of all hooves to monitor the temperature of coronary band. All images were scanned using a hand-held portable infrared camera (Wahl, Thermal Imager HSI3000 Series), which was calibrated to ambient temperature and absorptive conditions. Incentives radiological examinations, dorso-palmar and latero-medial shooting was done for using of (Regius Model 110 Konica, Minolta) $70 \mathrm{kV}$ and $30 \mathrm{mAs}$ for each claws. MRI images of all isolated digits were performed at the Department of Radiology, by using Siemens Symphony Erlangen, Germany. Continuous series of transversal, sagital and dorsoplantar scan were obtained from all digit. Computer tomography $(\mathrm{CT})$, isolated digits were performed at the Imaging Department of Radiology, by using Siemens Symphony Erlangen, Germany. CT scanner was used to obtain contiguous slices from the region of the proximal sesamoid bones to the toe. Anterior side (laminar and perilaminar tissues) of the claws was uncovered with electric wheel. Tissue samples were taken $10 \%$ buffered formaldehyde solution after establishing a routine laboratory procedure following the prepared paraffin blocks 5 micrometers thick sections with hematoxylineosin dye method according to the staining. It was finally examined by light microscopy. The computer soft ware of the infrared thermal camera showed increased local temperature, by $0.5-1.5^{\circ} \mathrm{C}$, between the normal and suspected regions for laminitic cases. Clinically, animals suspected of laminitis were showed general stiffness, lameness during walking difficulty. Examination of the claws was demonstrated of rings and plump appearance was evident in paries ungulae. The main damage was seen during trimming of the sole from no hemorrhages or discoloration of control group. The transversal MRI images provided excellent depictions of anatomical structures when compared to their corresponding pictures. Identifiable anatomic structure was labeled on the line drawings of the limb sections and on the corresponding CT images. Twenty out of 30 claws (65\%) were shown laminitis statistical with histopathological examination. In histopathological examination; mononuclear cells and neutrophil granulocytes infilrations and edema, haemorrhagia, mild hyperemia in the lamellar region was remarkable in laminitic cases.

Discussion: As a results, thermographic examination may have potential as a detection tool for laminitis. MR transversal images provided excellent depiction of anatomical structures and many biometric research in the bovine hoof can be easily investigated. The usefulness of IRT, MRI, CT in evaluating laminitis in the acute patient remains stil open. The use of diagnostic techniques during the initial active phase of laminitis as a means to increase the understanding of the disease and also serves as a justification for the development of an experiment involving live cows induces laminitis.
\end{abstract}

Keywords: bovine; CT, MRI, laminitis, radiography, thermography.

http://dx.doi.org/10.22456/1679-9216.85939 
M. Arican, F. Hatipoglu, H. Erol, et al. 2018. Comparison of Thermographic Imaging and Other Diagnostic Techniques

\section{INTRODUCTION}

Lameness results in major economic losses on dairy farms [6]. The proportion of lameness in cows are between $4-55 \%$, the origin of $90 \%$ lameness are caused by foot diseases [2]. Hoof abnormalities such as laminitis are major contributors to lameness [12,16,22].

Infrared thermography is a noninvasive technique capable of detecting thermal radiation from the surface of any object [21]. IRT may prove useful for early detection of laminitis, allowing interventions that could prevent or attenuate subsequent lameness [15]. Diagnostic imaging technique such as radiography and ultrasonograph provide limited information for evaluation of the bovine digits and hoof. Radiography has limited value to evaluation of soft tissue. Computed Tomography and MRI appear to be ideal method for examining the digital soft tissue and deep structures and appear to be a good tool in bovine lameness researches $[1,4,8,9,19]$. In bovine medicine like other large animals logistical problems at the present time, prevent to use the MRI as a diagnostic tool in live animals $[11,19,20]$. There are few reports on the clinical use of computed tomography in farm animals $[9,13]$. In valuable cattle, the results of CT can be an important part of preoperative planning or be used to avoid unnecessary surgery when the prognosis is poor [14].

In this study, thermographic imaging on the diagnosis of cow with laminitis was to evaluate for reliability of the diagnosis compare with radiographic, MRI, CT and histopathological analysis. Thus, one of the objective of this study was also to provide anatomic reference images of the normal and laminitic bovine digit using CT and MRI.

\section{MATERIALS AND METHODS}

\section{Animals}

Preliminary, the animals (20 Holstein-Fresian) were selected by lameness examination for evaluation of the for any obvious signs of disease. The animals were examined when rising and walking of the free stalls. Walking was very painful and clinical symptoms of general distress become present for laminitic group. The cows were scored on a 1 to 5 scale for their locomotion $(1=$ normal locomotion; $5=$ severely lame $)$ [Table 1]. All 2 claws of each cow (i.e., medial and lateral claws) were scored for sole hemorrhage and underrun heel. For sole hemorrhage, a combination of the scoring systems from Greenough and Vermunt [17] and Bergsten [18] were used. Thermographic examination was performed for these animals. After thermographic examination, the claws (40 claws) were signed and obtained from slaughter for clinical, radiological, MRI, CT and histopathological analysis.

\section{Infrared thermography examination}

Thermographic examinations were performed the all animals after the routine clinical examination methods. The infrared images were taken from the dorsal view of all hooves to monitor the temperature of coronary band. IRT images were captured several times. All images were scanned using a hand-held portable infrared camera (Wahl, Thermal Imager HSI3000 Series) $)^{1}$, which was calibrated to ambient temperature and absorptive conditions. Generally, the dorsal surface of hoof was cleaned for debris and moisture, before images were taken. Cows were moved to a free standing hoof-trimming stall and, after visual examination of hooves (10 to $20 \mathrm{~min}$ ), the IRT images were taken. Images were captured using a fixed $20^{\circ} \mathrm{C}$ range, and care was taken to ensure that the range of temperature over the hoof surface was within that range. To reduce the effects of environmental factors on thermal data, all images were scanned at the same distance (1.5 to $2 \mathrm{~m}$ ) from the subject.

Postmortem clinical, radiological examination and scoring systems

Vermunt and Greenough [22] and Bergsten [3] scoring systems were used. Fifteen feet (30 claws) were marked as a laminitic group and five ( 5 feet- 10 claws) of them has not been shown in temperature increase as a control groups.

\section{Radiological examinations}

Incentives radiological examinations, dorsopalmar and latero-medial shooting was done for using of (Regius Model 110 Konica, Minolta) ${ }^{2} 70 \mathrm{kV}$ and 30 mAs for each claws.

\section{Magnetic resonance images (MRI)}

MRI images of all isolated digits were performed at the Department of Radiology, by using Siemens Symphony Erlangen ${ }^{3}$. Continuous series of transversal, sagital and dorsoplantar scan were obtained from all digit. MRI images that most closely matched each gross section were compared to the corresponding gross anatomic section. Intensity and laminar separa- 
M. Arican, F. Hatipoglu, H. Erol, et al. 2018. Comparison of Thermographic Imaging and Other Diagnostic Techniques in Diagnosis of Cattle with Laminitis.

Acta Scientiae Veterinariae. 46: 1594

Table 1. Clinical, thermographic, radiological, MRI, CT and pathological results of cows with laminitis and normal.

\begin{tabular}{|c|c|c|c|c|c|c|}
\hline Animal & Clinical Diagnosis & Thermograhy & Radiology & MRI & CT & Patological Results \\
\hline 1 & Laminitis & + & $\begin{array}{l}\text { Osteophyte } \\
\text { Formation }\end{array}$ & Odema-Lamina & $\begin{array}{l}\text { Osteophyte } \\
\text { Formation }\end{array}$ & $\begin{array}{l}\text { Laminitis } \\
\text { Epitelial Necrosis }\end{array}$ \\
\hline 2 & Laminitis & + & $\mathrm{NC}$ & Odema & $\mathrm{NC}$ & Laminitis \\
\hline 3 & Laminitis & + & $\mathrm{NC}$ & $\mathrm{NC}$ & $\mathrm{NC}$ & Odema-Hyperemia \\
\hline 4 & Laminitis & + & $\begin{array}{l}\text { Osteophyte } \\
\text { Formation }\end{array}$ & Odema-Lamina & $\begin{array}{l}\text { Osteophyte } \\
\text { Formation }\end{array}$ & $\begin{array}{l}\text { Laminitis } \\
\text { Epitelial Necrosis }\end{array}$ \\
\hline 5 & Laminitis & + & $\mathrm{NC}$ & $\mathrm{NC}$ & $\mathrm{NC}$ & Normal \\
\hline 6 & Laminitis & + & $\mathrm{NC}$ & Odema & $\mathrm{NC}$ & Laminitis \\
\hline 7 & Laminitis & + & $\mathrm{NC}$ & $\mathrm{NC}$ & $\mathrm{NC}$ & Odema, Hyperemia \\
\hline 8 & Laminitis & + & $\begin{array}{l}\text { Osteophyte } \\
\text { Formation }\end{array}$ & Odema-Lamina & $\begin{array}{l}\text { Osteophyte } \\
\text { Formation }\end{array}$ & $\begin{array}{l}\text { Laminitis } \\
\text { Epitelial Necrosis }\end{array}$ \\
\hline 9 & Laminitis & + & $\mathrm{NC}$ & Odema & $\mathrm{NC}$ & Laminitis \\
\hline 10 & Laminitis & + & $\mathrm{NC}$ & $\mathrm{NC}$ & $\mathrm{NC}$ & Normal \\
\hline 11 & Laminitis & + & $\mathrm{NC}$ & $\mathrm{NC}$ & $\mathrm{NC}$ & Odema-Hyperemia \\
\hline 12 & Laminitis & + & $\begin{array}{l}\text { Osteophyte } \\
\text { Formation }\end{array}$ & Odema-Lamina & $\begin{array}{l}\text { Osteophyte } \\
\text { Formation }\end{array}$ & $\begin{array}{l}\text { Laminitis } \\
\text { Epitelial Necrosis }\end{array}$ \\
\hline 13 & Laminitis & + & $\mathrm{NC}$ & Odema & $\mathrm{NC}$ & Laminitis \\
\hline 14 & Laminitis & + & $\begin{array}{l}\text { Osteophyte } \\
\text { Formation }\end{array}$ & Odema-Lamina & $\begin{array}{l}\text { Osteophyte } \\
\text { Formation }\end{array}$ & $\begin{array}{l}\text { Laminitis } \\
\text { Epitelial Necrosis }\end{array}$ \\
\hline 15 & Laminitis & + & & & & \\
\hline 16 & Normal & - & $\mathrm{NC}$ & $\mathrm{NC}$ & $\mathrm{NC}$ & Normal \\
\hline 17 & Normal & - & $\mathrm{NC}$ & $\mathrm{NC}$ & $\mathrm{NC}$ & Laminitis \\
\hline 18 & Normal & - & $\mathrm{NC}$ & $\mathrm{NC}$ & $\mathrm{NC}$ & Normal \\
\hline 19 & Normal & - & $\mathrm{NC}$ & $\mathrm{NC}$ & $\mathrm{NC}$ & Hyperemia \\
\hline 20 & Normal & - & $\mathrm{NC}$ & $\mathrm{NC}$ & $\mathrm{NC}$ & Normal \\
\hline
\end{tabular}

NC: no change.

tion was graded normal, mild, moderate or severe [12]. Specific quantitative measurements of the MR images included; corium architecture (width of the corium), corium signal intensity, laminar architecture. Digital radiographs and MR images of the limbs were evaluated separately for evidence of laminitis and the resulting diagnoses were compared to the histopathological diagnosis for correlation.

\section{Computed tomography $(C T)$}

Isolated digits were performed at the Imaging Department of Radiology, by using Siemens Symphony Erlangen, Germany ${ }^{3}$. CT scanner was used to obtain contiguous slices from the region of the proximal sesamoid bones to the toe.

\section{Laminar tissues histopathologic analysis}

Anterior side (laminar and perilaminar tissues) of the claws was uncovered with electric wheel. Tissue samples were taken $10 \%$ buffered formaldehyde solution after establishing a routine laboratory procedure following the prepared paraffin blocks 5 micrometers thick sections with hematoxylin-eosin dye method according to the staining. It was finally examined by light microscopy.

Data analysis

A Chi-squared analysis was performed for each category at each level to detect any significant difference for the number values assigned for each category between normal and laminitic feet for thermography. A two-sample student's $t$-test was used to compare the mean differences in measurements obtained MR imaging, in normal and laminitic feet.

\section{RESULTS}

The comparison results of clinical diagnosis, thermography, radiology, MRI, CT and patological results was given Table 1. 
M. Arican, F. Hatipoglu, H. Erol, et al. 2018. Comparison of Thermographic Imaging and Other Diagnostic Techniques

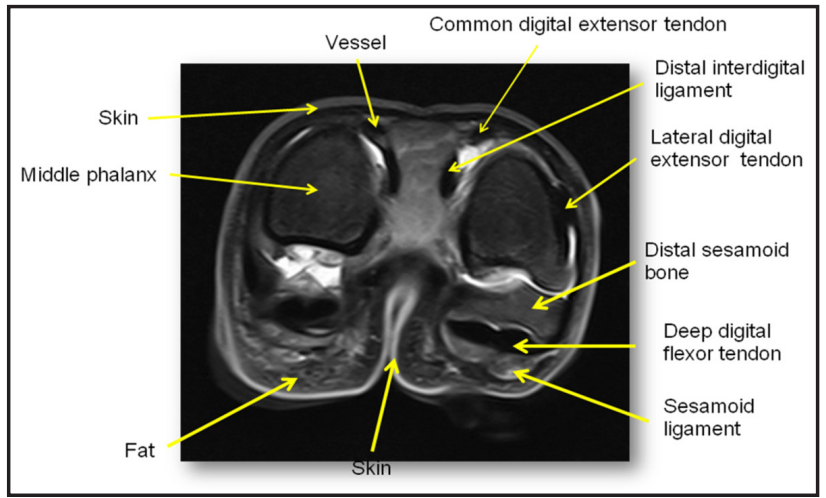

Figure 1. MRI images of cortex for phalanx, fat, skin and hoof.

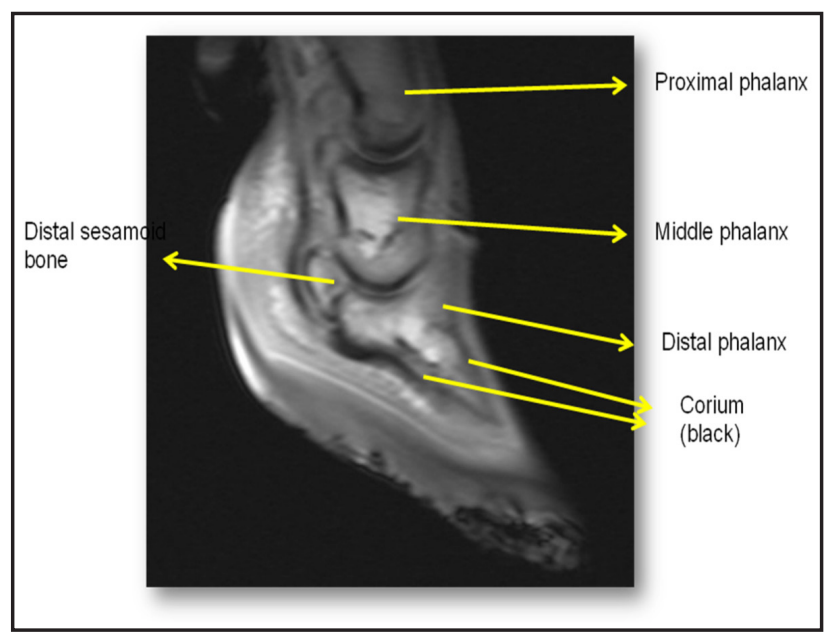

Figure 2. MRI images of tendons, blood vessels, synovial cavity and corium of hoof.

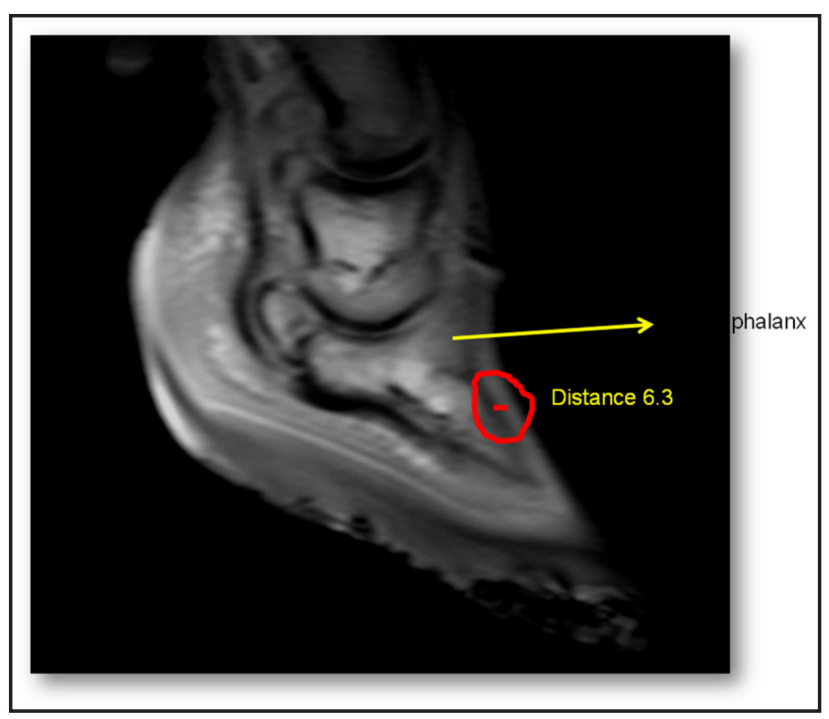

Figure 3. The architecture of the corium.

\section{Infrared thermography}

The computer soft ware of the infrared thermal camera showed increased local temperature, by 0.5 $1.5^{\circ} \mathrm{C}$, between the normal and suspected regions for laminitic cases.
Clinical, radiologic examination and scoring systems

Clinically, animals suspected of laminitis were showed general stiffness, lameness during walking difficulty. Examination of the claws was demonstrated of rings and plump appearance was evident in paries ungulae. The main damage was seen during trimming of the sole from no hemorrhages or discoloration of control group.

\section{Radiological}

Osteophitic formation was seen on extensorious processes in some cases.

\section{Magnetic resonans images}

The transversal MRI images provided excellent depictions of anatomical structures when compared to their corresponding pictures. In MRI images, cortex of phalanx, fat, skin and hoof were observed and had intermediate signal intensity and appeared grey (Figure 1). Tendons, blood vessels, synovial cavity and corium of hoof had a hyperintense signal and appeared black in MRI images (Figure 1 and Figure 2). Some cases included laminar disruption, circumscribed areas of laminar gas, laminar fluid and medullar fluid were seen, but not all laminitis suspected cases. The architecture of the corium was readily identifiable with a heterogeneous pattern (Figure 3).

\section{Computed tomography}

Identifiable anatomic structure was labeled on the line drawings of the limb sections and on the corresponding CT images (Figure 4). The CT and radiology results showed similarity to each other. It is only showed patological condition of 6 claws out of 30 claws. Especially, osteophyte formation in extensorious processes.

\section{Laminar tissues histopatologic analysis}

Twenty out of 30 claws (65\%) were shown laminitis statisticaly. In histopathological examination; edema, haemorrhagia and mild hyperemia in the lamellar region was remarkable in laminitic cases (Figure 5). Mononuclear cells infilrations with occasional neutrophil granulocytes were also found in these areas (Figure 6). In same cases, epitelial necrosis and mild perivascular haemorrhagia were also seen.

\section{DISCUSSION}

Infrared thermography is a modern, noninvasive and safe technique of thermal profile visualisation. 
M. Arican, F. Hatipoglu, H. Erol, et al. 2018. Comparison of Thermographic Imaging and Other Diagnostic Techniques

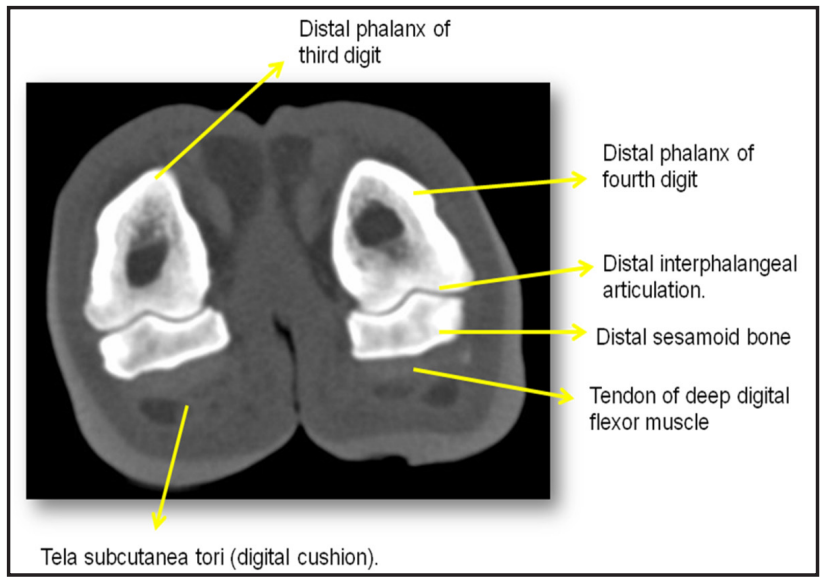

Figure 4. CT images of the hoof.

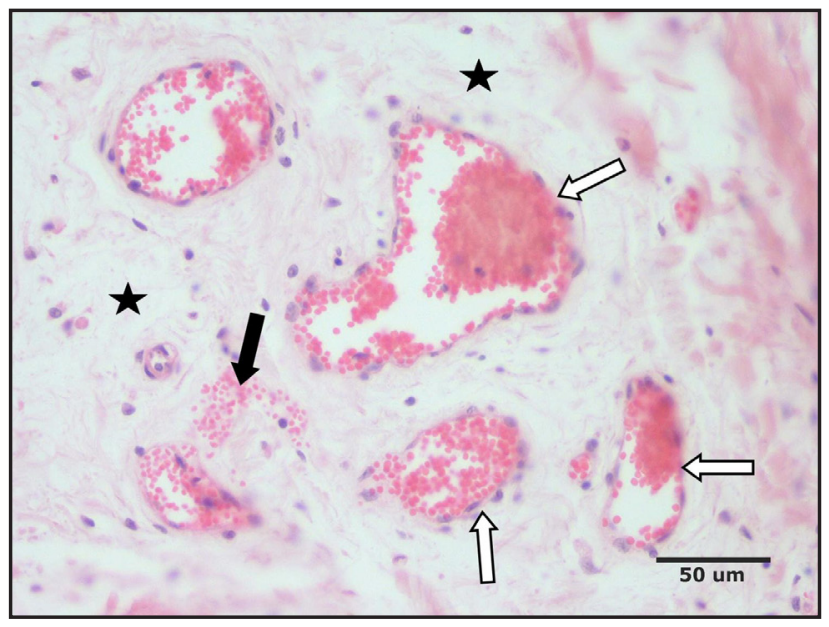

Figure 5. Edema $(*)$ haemorrhagia (black arrow) and mild hyperemia (white arrows) in the lamellar region. [ H\&E].

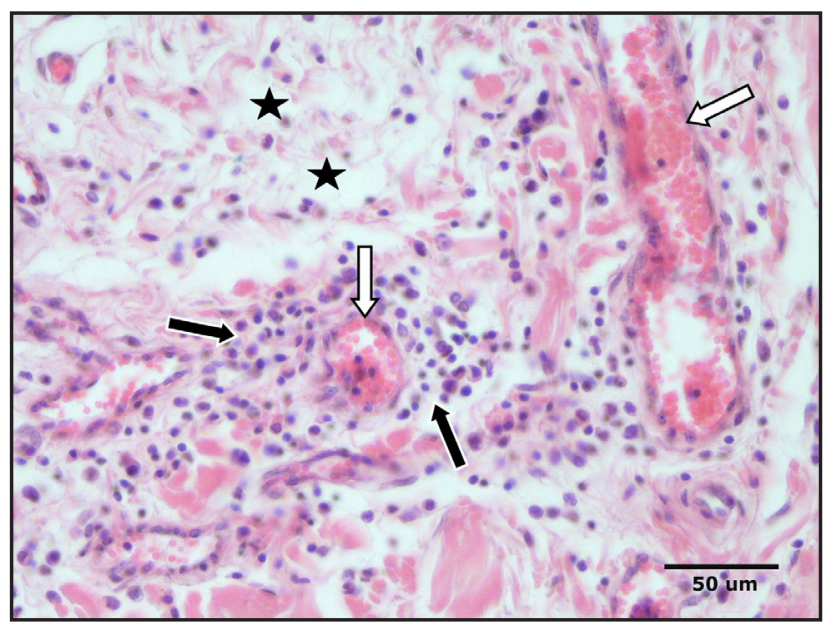

Figure 6. Mononuclear cells and neutrophil granulocytes infiltrations (black arrows), hyperemia (white arrows) and edema $(*)$. [ H\&E].

Thermographic method has found numerous applications not only in industry, but also in human and veterinary medicine, primarily for diagnostic purposes $[5,7,10]$. But IRT has been applied less frequently to research on livestock in live organisms, changes in vascular circulation result in an increase or decrease of tissue temperature, which is then used to assess the area [10]. In present study shows that thermography is an excellent adjunct to clinical and radiological examination. It has been considered that thermographic examination could be used safely for diagnosis of laminitis $(65 \%)$ under some condition. IRT can produce important information where the problem. Increased of the temperature can be explained with hyperemia by histopathological analysis. But there were some limitations and factors that need to be considered when using IRT. Thermograms must be collected out of direct sunlight and wind drafts. Hair coats should be free of dirt, moisture or foreign material. Beacuse of some of cases was shown laminitic appearance but patological results were not supported. It could be affected some moisture or foreign materials. It has been shown that the effect of weather conditions, circadian and ultradian rhythms, time of feeding, milking, laying, rumination, lactation and hoof location etc. were also factors that need to be considered and require further investigation as a part validating IRT $[5,7,10,16]$.

One of the purpose of this study was defining the normal and laminitic structures of the digits and hoof in Holstein dairy cattle using MRI. Transversal images provided excellent depiction of anatomical structures by MRI. MRI can not only be used in diagnostic procedures but also can be used in many biometric research, measurements and experimental [20]. In all of these cases, the corium of the hoof in normal cases at the present study appeared black and very easily identifiable. Laminar fluid, and bone medullary fluid was detected by MR in laminitic cases, but there was not seen any changes by radiography. Some laminitic cases were also shown that separation of corium. Examining the MR images in some cases, loss of normal corium architecture, loss of laminar architecture, increased signal intensity in the corium, increased signal intensity and separation in the laminae were identified. But, more cases should be use to understanding separation ratio properly normal and laminitic cases.

Computed tomography, much more information is becoming available to help evaluate circulation in feet $[17,18]$. It was shown similar results with radiological results but it needs contrast injection to get better visualisation.

IRT may have potential as a detection tool for laminitis. However, more data on the relationship between IRT and hoof abnormalities, preferably 
M. Arican, F. Hatipoglu, H. Erol, et al. 2018. Comparison of Thermographic Imaging and Other Diagnostic Techniques

in longitudinal studies, and further quantification of nonlaminitis factors affecting hoof temperature were required before IRT could be recommended for dairy industrial use as suggested by previous studies [10].

\section{CONCLUSION}

If infrared thermal measurements condition is suitable for examination, it could be very successfully in prediction, detection and diagnosis of diseases. The usefulness of thermography, MRI, CT in evaluating laminitis in the acute patient remains stil open this study evaluates the use of thermography, MRI, CT during the initial active phase of laminitis as a means to increase the understanding of the disease and also serves as a justification for the development of an experiment involving live cows induces laminitis.

\section{MANUFACTURERS}

${ }^{1}$ Wahl Instruments Inc. Asheville, NC, USA.

${ }^{2}$ Konica Minolta Business Solutions Italy S.p.A. Milano, Italy.

${ }^{3}$ Siemens Symphony. Erlangen, Germany.

Ethical approval. Animal procedures and experiments were approved by Ethics Committee of Experimental Medicine Research and Application Centre of Selcuk University.

Declaration of interest. The authors report no conflicts of interest. The authors alone are responsible for the content and writing of this paper.

\section{REFERENCES}

1 Arble J.B., Wassenaar P.A., Belknap J.K., Drost W., Weisbrode S.E., Schmalbrock P. \& Mattoon J.S. 2007. Evaluation of Initial Active Phase Laminitis in Equine Hoofs using MRI. Journal of Applied Animal Research. 28: 73-80.

2 Arican M. 2006. A colour atlas of diseases and operations in cattle surgery. Konya: Bahçıvanlar, pp.179-200.

3 Bergsten C. 1993. A photometric method for recording hoof diseases in cattle, with special reference to hemorrhages of the sole. Acta Veterinaria Scandinavica. 34: 281-286.

4 Ehlert A., Ferguson J. \& Gerlach K. 2011. Magnetic resonance imaging and cross-sectional anatomy of the normal bovine tarsus. Anatomia Histologia Embryologia. 40: 234-240.

5 Embaby S., Shamaa A.A. \& Gohar H.M. 2002. Clinical assessment of thermography as a diagnostic and prognostic tool in horse practice. In: Proceedings of the 1st Inframation (Orlando, USA). pp.30-36.

6 Green L.E., Hedges V.J., Schukken Y.H., Blowey R.W. \& Packington A.J. 2002. The impact of clinical lameness on the milk yield of dairy cows. Journal of Dairy Research. 85(9): 2250-2256.

7 Harper D.L. 2000. The value of infrared thermography in a diagnosis and prognosis of injuries in animals. In: Proceedings of the 1st Inframation (Orlando, USA). pp.115-122.

8 Holló G., Szúcs E., Tőzsér J., Holló I. \& Repa I. 2007. Application of x-ray computer tomography (CT) in cattle production. Asian Australasian Journal of Animal Science. 20(12): 1901-1908.

9 Kazer-Hotz B.S., Sartoretti-Schefer S. \& Weiss R. 1994. Computed tomography and magnetic imaging of the normal equine carpus. Veterinary Radiology Ultrasound. 6: 457-461.

10 Knížková I., Kunc P., Koubkova M., Flusser J. \& Dolezal O. 2002. Evaluation of naturally ventilated dairy barn management by a thermographic method. Livestock Produce Science. 77: 349-353.

11 Lee K., Yamada K., Tsuneda R., Kishimoto M., Shimizu J., Koboyashi Y., Furuoka H., Matsui T., Sasaki N., Ishii M., Inokuma H., Miyake N. \& Iwasaki T. 2009. Clinical experience of using multidetector-row CT for the diagnosis of disorders in cattle. Veterinary Record. 165(19): 559-562.

12 Moore R.M., Eades S.C. \& Stokes A.M. 2004. Evidence for vascular and enzymatic events in the pathophysiology of acute laminitis: which pathway is responsible for initiation of this process in horses. Equine Veterinary Journal. 36(3): 204-209.

13 Mohamed T., Al-Sobayil F., Kurwasawa T., Nakade T. \& Floeck M. 2011. Computed tomographic findings in a calf with actinomycosis: a case report. Veterinarni Medicana. 56(5): 255-259.

14 Nuss K., Schnetzler C., Hagen R., Schwarz A. \& Kircher P. 2011. Clinical application of computed tomography in cattle. Tierarztl Prax Ausg G Grosstiere Nutztiere. 39: 317-224.

15 Nikkah A., Plaizier J.C., Einarson M.S., Berry R.J., Scott S.L. \& Kennedy A.D. 2005. Infrared thermography and visual examination of hooves of dairy cows in two stages of lactation. Journal of Dairy Research. 88(8): 2479-2753.

16 Nocek J.E. 1997. Bovine acidosis: Implications on laminitis. Journal of Dairy Research. 80(5): 1005-1028.

17 Paulus M.J., Gleason S.S., Kennel S.J., Hunsicker P.R. \& Johnson D.K. 2000. High resolution X-ray computed tomography: an emerging tool for small animal cancer research. Neoplasia. 2(1-2): 62-70. 
M. Arican, F. Hatipoglu, H. Erol, et al. 2018. Comparison of Thermographic Imaging and Other Diagnostic Techniques in Diagnosis of Cattle with Laminitis.

18 Paulus M.J., Gleason S.S., Eastery M.E. \& Folts C.J. 2001. A review of high resolution x-ray computed tomography and other imaging modalities for small animal research. Laboratory Animals. 30: 36-45.

19 Raji A.R., Sardari K. \& Mohammadi H.R. 2008. Normal cross-sectional anatomy of the bovine digit; Comparison of Computed Tomography and limb anatomy. Anatomia Histologia Embryologia. 37: 188-191.

20 Raji A.R., Sardari K. \& Mirmahmoob P. 2009. Magnetic resonance imaging of the normal bovine digit. Veterinary Research Communications. 33(6): 515-520.

21 Schaefer A.L., Cook N., Tessaro S.V., Deregt D., Desroches G., Dubeski P.L., Tong A.K.W. \& Godson D.L. 2003. Early detection and prediction of infection using infrared thermography. Canadian Journal of Animal Science. 84(1): 73-80.

22 Vermunt J.J. \& Greenough P.R. 1995. Structural characteristics of the bovine claw: Horn growth and wear, horn hardness and claw conformation. British Veterinary Journal. 151: 157-180. 